\title{
Study on Internet Financial Risk Early Warning Based on Big Data Analysis
}

\author{
YU SHEN \\ SCHOOL OF INTERNATIONAL ECONOMICS OF GUIZHOU UNIVERSITY OF F\&E;GUIZHOU, \\ GUIYANG 550025, China \\ YuSHEN109@yeah.net
}

Keywords: data analysis; Internet finance; financial risk; risk warning

\begin{abstract}
Big data analysis and Internet financial are currently the most fiery words. The perfect use of big data and Internet in the financial industry will undoubtedly bring a huge change to the entire financial industry. But the opportunities and risks of Internet financial are coexist, whose risk is greater than traditional financial sector because of its integration with the network and it is very important to do well in financial risk early warning. This paper analyzes the Internet financial risk early warning mechanism and propose specific measures .
\end{abstract}

\section{Introduction}

Currently, the big data era has come, the massive accumulation of data urgently need data processing and large data analysis emerged. At the same time, Alibaba, Tencent and other Internet giants have set foot in financial services, Alipay, the representative of all types of Internet financial products have emerged, the Internet financial based on large data analysis are growing . Large number of customers turn financial resources to the Internet to obtain a high investment return of and widely focus on the study of Internet financial risk.

\section{An Internet-based financial characteristics and advantages of big data analysis}

Big data analysis analyze data through statistical methods and obtain something valuable to play the role of the data. Internet finance combine the traditional financial services with the Internet and bring you a new experience. Internet financial analyze based on large data. Admittedly, the Internet has its own financial advantage.

Internet covers large area and various systems links with each other. information sharing easy data transfer can solve asymmetric information. Internet has creation in payments, credits, deposits areas, etc. Efficient transaction break through the restrictions of geographical distance and time to facilitate the lives of the masses and shock traditional financial services of traditional financial sector .

Big data analysis-based Internet financial risk early warning mechanism also has widely characteristics-- not for specific businesses, wide caliber, suitable for most enterprises' risk warning, highly application. Therefore, this mechanism can play an important role in the various industries, especially with the development of network communication technology, more and more industries and large companies have introduced big data analysis in risk early warning and control, the following are some typical. 


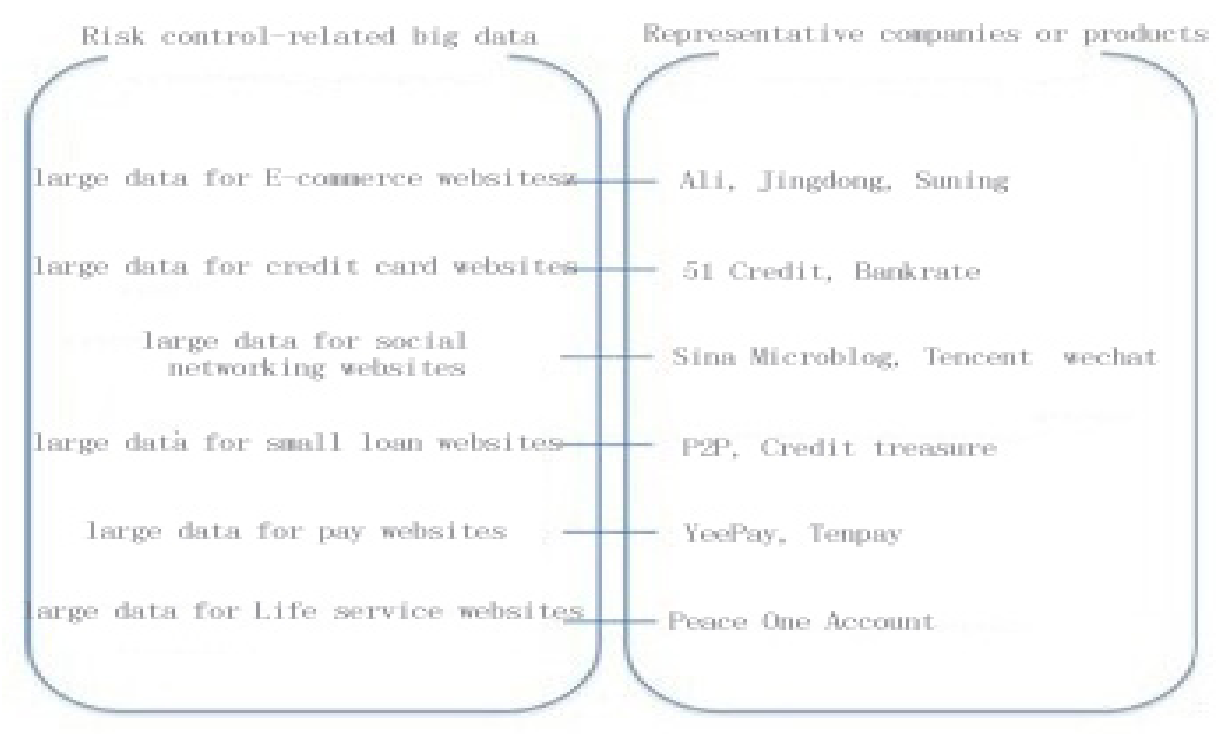

Figure 1 Application of big data analysis-based Internet financial risk early warning in all walks of life

\section{Internet financial risk based on large data analysis}

\section{Credit risk}

After all, Internet financial is also an emerging thing and the assorted legal system is still not perfect. The credit system construction has yet to be further strengthened and the qualification requirements of registered enterprises is not stricted as well as bank and entry barriers are uneven. there are loopholes in the customer identification and we can not rule out some registration qualification enough resulting credit risk, and even use the Internet to engage in money laundering and other financial crime. Under normal circumstances, the mainstream Internet financial software, such as Paypal, by way of third-party payment, to a certain extent, reduce the credit risk, but credit risky for some companies is also huge due to various reasons such as capital, technology and other third-party itself does not have the ability to pay.

\section{Privacy risks}

In the network, data information can flow efficiently and quickly but also has the risk of leakage, for example, account information needs investors' detailed identity information, such as bank account number, bank account passwords, phone numbers, home addresses and so on, whose leakage will bring investors immeasurable loss. Some software needs to bound phone and complete series of transaction by cell phone verification code. If the phone is lost, privacy is lost, which will threaten property.

\section{Technical risk}

Internet Finance, based on Internet big data analysis, must make the proper function of the Internet as a precondition. And the network environment needs to be further optimized. Network financial crime is serious. Under the circumstances of hacker attacks, network viruses, network technology failure, the network can not operate normally, which bring the risk of financial losses. And the risk is huge and is difficult to be timely controlled. 


\section{The early warning mechanism of the financial risk}

\section{Analysis of early warning signals}

Early warning signs are often the harbinger of financial risks. Concerns on the risk of early warning signals can predict state development trend before the arrival of risk and take effective measures for risk management. Some early warning signals are very clear, such as damage to corporate reputation, major changes of financial condition and other can be made very clear judgment. Some signals, such as financial statements, policy changes, and so on, need policy makers to determine, analyze and make the right interpretation. In short, analysis and judgment for the early warning signals risk is a more intuitive way in the mechanism.

\section{Design of early warning indicator system}

The establishment of a scientific index system is the primary basis of financial risk early warning analysis. We hope that we can analyze them through a series of data and grasp the outbreak precursor of financial risk and make a warning before the risk to avoid risks. The selection of indicators should follow certain principles, such as measurable, controllable, relevant, interference, representative, etc., which is easy to get the data, and sensitively response to Internet financial risks. We can establish index system from three aspects of macroeconomic financial indicators, medium economic and financial indicators, micro-economic and financial indicators and make early warning for different systems.

\section{Application process of Big data analysis-based Internet financial risk early warning mechanism}

Before the collection and processing of formal data materials, deepen the understanding of the business and data, plan which data to select, use what kind of data collection and processing methods, this preparation is essential. Obtained data materials basically include basic information, account information, water data and other relevant data, which is the preliminary data and is more chaotic, and it can not be directly applied, it must be processed. The next data mining processing can solve this problem, in different problems, according to the requirements of different risk models, conduct different processing to the data and form data products. This process combines the use of high technology and computer index system, analyzed vast amounts of big data, which is a very critical step. After getting the right data, move to the final application stage of the Internet enterprise financial risk early warning mechanism and control. It is worth noting that these data not only play an important role in timely warning the potential business risks, timely controlling the risk and reducing the risk, but also has a far-reaching significance in the enterprise decision, forecasting and assessment and other aspects.

\section{Analysis on the risk warning measurements}

\section{Scientific Data indicator system and assessment system}

Scientific risk monitoring system assessment must make the data as core, and quantitative description indicators as testing standards and timely handle achieving early warning indicators. Specific steps are, firstly select the appropriate indicators and establish an index system having strong correlation with a set of financial risk changes, and then select the early warning value of various indicators and forecast based on experience, and finally with the numerical Internet monitoring financial risk. Participants must rely on the assessment of inspection data system, quantitative assessment mechanism, strict reward and punishment system, the participants of the indicators are in the target within an appropriate reward or reduced inspection frequency, the risk of early warning indicators of indicators have reached worthwhile to take increased inspection frequency, interview conversation, requires reflection reasons, called for corrective measures such as treatment-specific measures.

\section{Trinity risk early-warning monitoring network}

Monitoring for risk early warning needs coordination and cooperation, mutual restraint, 
among departments, the regulation of financial regulatory sector, self-regulation within the industry, the public oversight cooperate with each other. To form a trinity risk early warning monitoring network is an effective regulatory program. Regulatory authorities play a guiding role and develop goals and norms, co-ordinate the establishment and maintenance work of the early warning mechanism. The financial sector should develop internal management systems based on its own development and risk prevention measurements to specifically implement early warning work of Internet financial risks. Of course, to make the early warning monitoring network play a significant role is also inseparable from the supervision of the masses.

\section{Complete legal system protection}

Healthy sustained developing Internet financial must run within the framework of laws and regulations, but also needs the government's policy support and mutual supervision, self-management of investors. Create a healthy and fair environment to protect financial security of Internet financial investors. Government should strengthen legislation and law enforcement supervision, develop specific regulations, such as the establishment of large capital reporting system, suspicious transaction reporting system, etc. take technology for emergencies or suspicious events to suspend or delay the transaction. We should regulate all actions and make specific provision, such as the required specific documents customer identity verifying when accounting, etc. , to urge the various participants consciously strengthen risk early warning and achieve penalties for illegal participants to improve the regulatory capacity .

\section{Conclusion}

In summary, we must establish a sound financial risk early warning systems and mechanisms and take effective measures to prevent risks and to ensure the normal operation of Internet banking. The financial risk early warning system based on large data will rapidly develop under the financial Internet era background.

\section{References}

[1] Xu Jie, Wei Binxian, Jie Xiaowen. Research on Internet Finance and Small and Micro Enterprises Financing Innovation[J] Business Economics and Management, 2014,04: 92-96.

[2] Liu Yun, Zhu Ruibo. Internet Banking, Small and Micro Enterprise Financing and Credit System Deepening [J] Credit, 2014,02: 31-35.

[3] Yang Hu, Yi Danhui, Xiao Hongwei. Study on large Internet financial risk early warning based on data analysis [J] Modern Management Science, 2014,04: 3-5.

[4] Cao Yanling. Study on Internet Financial Risk Evaluation Based on Fuzzy Hierarchy Analysis [D]. University of Science and Technology of China, 2014.

[5] Kang Bo. Liu Shengqiang. Internet Business User Experience Management Based on Large Data Analysis [J] Telecommunications Science, 2013,03: 32-35. 